\title{
Impact of crystalloids and colloids on coagulation cascade during trauma resuscitation-a literature review
}

\author{
Jakub Kaczynski ${ }^{1 *}$, Maria Wilczynska², Joanna Hilton ${ }^{1}$ and Louis Fligelstone ${ }^{1}$ \\ *Correspondence: jakub.kaczynski@hotmail.co.uk \\ 'ABM University Health Board, Regional Trauma Centre, General and Vascular Surgery Departments, Morriston Hospital, \\ Swansea, SA6 6NL, UK. \\ ${ }^{2}$ Hywel Dda Health Board, General Medicine Department, Prince Phillip Hospital, Llanelli, SA14 8QF, UK.
}

\begin{abstract}
Background: During resuscitation trauma patients receive various intravenous fluids, which can exacerbate coagulopathy and haemorrhage further. This led to the introduction of the damage control resuscitation, which advocates minimal intravenous fluids use. However, some fluid may be required in uncontrolled haemorrhage or when blood products are not immediately available. Furthermore, questions regarding the type and volume of the administered fluids remain still unanswered.

Methods: Review of literature.

$\underline{\text { Results: }}$ Crystalloids such as $0.9 \%$ Isotonic Saline and Lactate Ringers can cause either a hypercoagulable (lower dilutions) or hypocoagulable (higher dilutions) derangements. Hypertonic Saline (7.5\%) leads to more pronounced coagulation abnormalities when compared with $0.9 \%$ Isotonic Saline. The effects of the 7.5\% Hypertonic Saline combined with $6 \%$ Dextran 70 are controversial. Some authors reported significant clotting abnormalities, but others found an improvement in the haemodynamic parameters. The evidence on human albumin solution use in trauma is very limited and suggests a procoagulant effect at lower dilutions. Gelofusine even with smaller volumes leads to pronounced coagulation abnormalities. All Dextrans (40 and 70$)$ cause significant hypocoagulability at lower dilutions. Similarly lower molecular starches demonstrate a definite hypocoagulable effect. Conclusions: A literature review has also indicated that none of the studies demonstrated survival or outcome benefit associated with a particular type and volume of administered intravenous fluids. The results are controversial and further research is needed to clarify this issue.
\end{abstract}

Keywords: Albumins, coagulopathy, dextran, gelofusine, hypertonic saline, $0.9 \%$ isotonic saline, lactate ringers, $6 \%$ voluven

\section{Introduction}

The acute coagulopathy of trauma (ACT) is associated with significant mortality and increases the risk of haemorrhage further $[1,2]$. It can be caused by the loss of coagulation factors due to haemorrhage, hypothermia, acidosis, trauma and dilution from the intravenous fluids (IVF) administration [3-5]. The circulatory system can be viewed as an electrical circuit $(P=F \times R)$ in which $P$ represents pressure difference between the two ends of the vessel, $\mathrm{F}$ is blood flow and $\mathrm{R}$ is called the vascular resistance [6]. This Ohm's law explains why aggressive resuscitation with IVF may inadvertently lead to more blood loss. This is due to an increase of pressure in the damaged blood vessels resulting in the disruption of the formed blood clot $[7,8]$. Despite this simple logic, the past management of trauma patients for many years was based on the belief that the use of large volumes of intravenous crystalloids is essential to restore the circulating volume and to achieve the best outcomes [9]. However, several studies found this to be harmful, because it exacerbates the lethal triad (acidosis, coagulopathy and hypothermia) and shock induced inflammatory response [10-12]. This subsequently leads to profound systemic and cellular complications, which cause adult respiratory distress syndrome (ARDS), multi organ dysfunction syndrome (MODS) and death $[12,13]$.

Fluid resuscitation strategies have evolved substantially over the past decade leading to the introduction of the Damage Control Resuscitation (DCR) model. DCR aims to salvage the trauma patient from disturbed physiology by breaking the lethal triad [14]. DCR utilises three key concepts: permissive hypotension, rapid correction of the coagulopathy and early use of blood products as primary resuscitation fluids (instead of IVF) $[8, \mathbf{1 1}]$. This appears to be logical giving the fact that all fluids including crystalloids and colloids have the ability to worsen the shock and coagulopathy [15]. One might even argue that we should stop using crystalloids and colloids all together. However, this would be neither a safe nor a practical option, mainly, because some fluid is needed to maintain the systolic blood pressure $(80-90 \mathrm{mmHg}$ or palpable radial pulse) in order to continue perfusion of the vital organs (heart and brain) at the expense of worsening peripheral perfusion. This is particularly true when faced with uncontrolled bleeding, for example, during the pre-hospital phase and when blood is not available. This approach has been augmented by the research, which showed that small boluses of crystalloids $(250 \mathrm{mls}$ ) administrated in a controlled manner are beneficial during an active haemorrhage [16]. On the other hand, the fundamental 
questions regarding the volume and type of the fluids infused remain still unanswered. Even an updated Advanced Trauma Life Support (ATLS) manual finds it difficult to estimate the amount of intravenous fluids needed during resuscitation [9]. The most logical approach to administration of intravenous fluids appears to be based on patients' haemodynamic parameters and response to resuscitation [16]. Nevertheless, there is enough evidence that the administration of IVF during trauma can have detrimental effects on coagulation cascade. Hence, the knowledge of the IVF induced coagulopathy has an important clinical relevance. This article summarises the current evidence on coagulation cascade derangement caused by various crystalloids and colloids.

\section{Effect of intravenous fluids on coagulation}

In general available fluids are divided into two groups: crystalloids and colloids [7]. The crystalloids include isotonic, hypertonic solutions and combination of hypertonic solutions with Dextran. The colloids are subdivided into natural (albumin) and synthetic (Dextran, Gelatine and Starch).

\section{Crystalloids: 0.9\% Isotonic Saline and Lactate Ringers} Crystalloids have been the main resuscitation fluids for more than 70 years $[17,18]$. They became popular during the Vietnam War, when blood became unavailable. Initially their use was thought to be associated with better survival [13]. However, their use soon became associated with the "shocked lung", which later on was defined as ARDS [18]. Numerous in vitro studies proved that $0.9 \%$ Isotonic Saline (IS) at lower dilutions (10\%) acts as procoagulant, but has an anticoagulant effect at higher dilutions $[19,20]$. Roche et al., replicated the above findings by demonstrating an increased r-time (reaction time, which corresponds to an early clot formation) and reduced a-angle (indicator of the rate of solid clot formation) in thromboelastography (TEG) at higher dilutions (40-60\%), which are consistent with the hypocoagulable state. Coats et al., proposed a purely dilutional effect of IS as a primary explanation for this coagulation derangement. However, other authors link it with the impairment of thrombin formation and fibrin polymerisation by the administered large crystalloid volume $[\mathbf{2 1}, \mathbf{2 2}]$. The hypercoagulability could be explained by the presence of an imbalance between decreased antithrombin III (ATIII) activity and thrombin generation [23]. The IS induced haemodilution, which also results in Platelets (PLT) aggregation, leads to thrombin generation, which subsequently binds with an ATIII [23]. Consequently, consumption of ATIII results in the development of hypercoagulability.

Similarly, Lactate Ringers (LR) demonstrated a hypercoagulable effect at $20 \%$ dilution, but hypocoagulable properties with prolonged $r$-time and reduced $\mathrm{a}$ - angle at dilutions $>40 \%$ $[24,25]$. In spite of these similarities with IS, several differences and controversies surround these two crystalloids.

The $\mathrm{pH}$ of $0.9 \%$ IS is only 5 and along with the high sodium and chloride load is responsible for the development of the hyperchloraemic metabolic acidosis [11]. Surprisingly, despite the presence of the two isomers of Lactate Acid (D and $\mathrm{L}$ ), $\mathrm{LR}$ with the $\mathrm{pH}$ of 6.5 is more alkalising solution than IS $[10,18]$. The isomer $L$ is a naturally occurring one, so can be easily metabolised by the body [24]. In contrast, D-isomer, which cannot be metabolised, is associated with neutrophils activation and subsequently leads to the development of systemic inflammatory response syndrome (SIRS) $[11,17,26]$. LR cannot be used for infusion with red blood cells, because it leads to the clotting of the blood filters due to calcium citrate content [11]. Also, the presence of potassium can worsen hyperkalemia [26]. All of the above would seem to favour IS, but conflicting results from various studies make it almost impossible to draw the definite conclusions. Some studies advise LR as the primary resuscitation crystalloid, having fewer reported complications with its use in trauma $[10,13,17]$. Interestingly, no association was found between LR and the degree of acidosis [26]. However, a Cochrane review demonstrated no obvious advantage of one of these crystalloids over the other [27].

\section{Hypertonic Saline (HTS)}

In the 1980s Hypertonic Saline (HTS) was introduced as a small volume alternative to the large volume of crystalloids used during the resuscitation $[10,28]$. Although this fluid is available in several concentrations (3\%, 3.5\%, 5\% and 7.5\%), the majority of the available data is based on the $7.5 \%$ HTS solution. Animal models of uncontrolled haemorrhage (grade V liver injury) showed that 3\% HTS is able to maintain mean arterial pressure at higher levels than LR [29]. 3\% HTS was also associated with reduced lung and intestinal complications [29]. DuBose et al., reported reduced mortality after $5 \% \mathrm{HTS}$ in patients with Glasgow comma scale $(\mathrm{GCS})<8$, but this did not seem to translate to improvement in neurological function 6 months post traumatic brain injury [30].

The benefits of $7.5 \%$ HTS were reported to be superior to lower HTS concentrations [29]. 7.5\% HTS is associated with the reduction of intracranial pressure in head injuries and fewer complications, such as ARDS or sepsis $[\mathbf{1 1 , 3 1 , 3 2 ]}$. It has the potential of increasing blood pressure with lower volumes $(250 \mathrm{mls})$ due to rapid shifts of the fluid between the cellular and interstitial spaces $[\mathbf{2 9}, \mathbf{3 1}, \mathbf{3 3}]$. On the other hand, it carries a risk of the cellular dehydration due to high sodium load and central pontine myelinosis $[30,31]$. More importantly, the coagulation derangement is much more pronounced when compared with IS. The increase in the r-time and reduced a-angle are noted even at the low $10 \%$ dilution [33].

\section{Hypertonic saline with dextran (HSD)}

$7.5 \%$ Hypertonic Saline combined with $6 \%$ Dextran 70 (HSD) was thought to be another compelling option. Unfortunately, many studies delivered conflicting results. Mattox et al., found that HSD is safe, and associated with a lower incidence of coagulopathy. In contrast, Coats et al., revealed the HSD 
procoagulant effect at $10 \%$ with subsequent rapid increase in deranged clotting at $15 \%$ dilution [34]. Rotstein et al., suggested that a small bolus of HSD can be beneficial in haemorrhagic shock, but other research group found that it is associated with a risk of inducing splanchnic ischaemia [13]. Similarly to HTS, the evidence shows that HSD can improve haemodynamic parameters and reduce intracranial pressure [35]. Unfortunately, so far none of the studies demonstrated survival or outcome benefit associated with the use of HTS or HSD and further research is needed to clarify this issue $[13,16,35,36]$.

\section{Natural colloids}

Human Albumin Solution (4.5\% and 20\%)

The evidence on human albumin solution (HAS) use is limited, and results are controversial [37]. No data are available on the $20 \% \mathrm{HAS}$ and its effect on coagulation cascade. The $4.5 \%$ HAS has similar procoagulant effect as IS at $10 \%$ dilution [38]. However, Vogt et al., revealed minimal coagulation derangement. Roche et al., found prolonged r-time and reduced MA (maximum amplitude representing strength of the clot) values at $40 \%$ dilution with $4.5 \%$ HAS. He also showed significantly reduced calcium levels, which can worsen the coagulopathy further. HAS is not routinely used in trauma (except burns) due to the high price, risk of disease transmission and their association with an increased mortality in patients with traumatic brain injury $[10,39,40]$.

\section{Synthetic colloids}

The synthetic (non-protein) colloids are classified into gelatines, dextran solutions and hydroxyethyl starches. The current evidence from meta-analyses showed an increased risk of death in trauma patients resuscitated with colloids $[16,22]$. However, a Cochrane review suggested no differences between crystalloids and colloids [27].

\section{Gelofusine}

Uniform results from multiple in vitro studies confirm profound anticoagulant effects of Gelofusine with $40 \%$ and $60 \%$ dilution, which is similar to the one found in patients receiving heparin during haemodialysis $[19,21,39,41,42]$. In vivo, Gelofusine demonstrated greater dilution when compared to IS and overall smaller volume leads to more pronounced coagulation derangement $[\mathbf{4 1 , 4 2 ]}$. In addition, Gelofusine can cause anaphylactic reactions due to its bovine collagen component [41]. This is believed to be caused by an intrinsic effect of Gelofusine owing to its negative charge [19]. The negative Gelofusine charge interferes with negatively charged phospholipids on PLT by covering the PLT membrane with the colloid's macromolecule [42]. This reduces adhesion and aggregation of PLT resulting in the derangement of the coagulation [42]. However, other authors imply that Gelofusine might influence the weight and reticular network of fibrin strands, due to incorporation of gelatine molecules into the developing clot [22].

\section{Dextran 40 and 70}

The available Dextrans are 40 and 70 (Molecular WeightMW) [39]. Only a few studies in the literature have examined the effect of Dextran 40 and 70 on coagulation profile. All studies report an increased coagulation at $20 \%$ dilution with hypocoagulability above $40 \%$ dilution with prolongation of the r-time and reduction in MA with Dextran $70[34,38]$. Petroianu et al., reported profound hypocoagulable states at $50 \%$ dilution with Dextran 40.

\section{6\% Voluven}

There are many generations of starches, including 200/0.5, $250 / 0.5,450 / 0.7$ and the most frequently used 130/0.4 (6\% Voluven) $[23,39]$. The particular generation is described by the MW and the degree of molar substitution $[39,43]$. For example, $6 \%$ Voluven has a MW of 130 and a molar substitution of 0.4. Trumble et al., suggested that a higher MW leads to a more significant coagulation derangement. However, others proposed that lower molar substitution, allowing for increased starch elimination, minimises the harmful effect on coagulation $[22,44]$.

It remains debatable whether the benefit comes from the lower MW or lower molar substitution. Nevertheless, lower MW starches have shown fewer negative effects such as renal failure and coagulopathy [39]. A hypocoagulable effect of $6 \%$ Voluven was revealed in vitro at $40 \%$ and $50 \%$ dilution by prolongation in $r$-time and reduced $\alpha$ - angle and MA value $[24,38]$. Recent studies despite their poor design and lack of statistical significance showed that $6 \%$ Voluven reduced mortality with no evidence of coagulopathy in trauma [45-47]. James et al., found that $6 \%$ Voluven is associated with better lactate clearance and with no evidence of renal failure. However, this was not the case in the blunt trauma group who in general sustained more severe injuries and were more coagulopathic. It is therefore, unclear whether the presence of ACT in this group of patients prevented them from having any benefit from the $6 \%$ Voluven [48]. The significant hypocoagulable effect of the starch could be explained by the blockade of the fibrinogen receptor (Gllb-Illa) by macromolecules of $6 \%$ Voluven [22]. Therefore, as a consequence impaired PLT function with reduced von Willebrand's factor level impairs fibrin polymerisation leading to coagulopathy.

\section{Conclusions}

Haemorrhaging polytrauma victims represent the most vulnerable group of patients. Their survival depends on prompt haemorrhage recognition and appropriate resuscitation. An extensive literature review revealed that both crystalloids and colloids can alter coagulation cascade by dilution and intrinsic effects $[10,17,19-21,23,24,26,29-31,33,34,38-42$, 44-58]. The exact mechanisms by which intravenous fluids 
cause coagulation impairment are still poorly understood. Furthermore, the idea of an "ideal" intravenous fluid which would offer oxygen carrying capacity, volume replacement and minimal haemostasis derangement remains elusive. Nevertheless, some fluid replacement therapy may be required when a multiple injured patient suffers from an uncontrolled haemorrhage $[16,59]$. Although, some evidence supports the use of small volume $(250 \mathrm{mls})$ IVF administration in uncontrolled haemorrhage, the results of many studies are controversial and should be interpreted with caution. Crystalloids and colloids are used on daily basis in many surgical and medical specialties. Therefore, knowledge of and the effect of commonly administered fluids on the coagulation process have an important clinical relevance beyond trauma. Future research is required to further clarify this issue.

\section{List of Abbreviations}

ACT: Acute coagulopathy of trauma

ARDS: Adult respiratory distress syndrome

ATIII: Antithrombin III

ATLS: Advanced Trauma Life Support

DCR: Damage Control Resuscitation

GCS: Glasgow comma scale

HAS: Human albumin solution

HSD: Hypertonic Saline with Dextran

HTS: Hypertonic Saline

IS: $0.9 \%$ Isotonic Saline

IVF: Intravenous fluids

LR: Lactate Ringers

MA: Maximum amplitude

MODS: Multi organ dysfunction syndrome

MW: Molecular Weight

PLT: Platelets

SIRS: Systemic inflammatory response syndrome

TEG: Thromboelastography

\section{Competing interests}

The authors declare that they have no competing interests.

\section{Authors' contributions}

Corresponding author's statement: There won't be

any further changes in the authorship, which includes

either addition or removal of author's detail. The

corresponding author is solely responsible person for all

the communications and proceedings that are needed to

be done with the publisher on behalf of all authors.

JK and MW carried out the literature search, critical

appraisal of the evidence and drafted the manuscript.

$\mathrm{JH}$ and LF carried out the critical revision of the

manuscript and helped to re-draft it.

Final manuscript was read and approved by all authors.

Publication history

Received: 07-Mar-2013 Accepted: 29-Mar-2013

Published: 02-Apr-2013

\section{References}

1. Jeger V, Urwyler $\mathrm{N}$, Zimmermann $\mathrm{H}$ and Exadaktylos AK: Trauma-induced coagulopathy in severely injured patients: knowledge lost in translation? Emerg Med J 2010, 27:551-2. | Article I PubMed

2. Frith $D$, Davenport $R$ and Brohi K: Acute traumatic coagulopathy. Curr Opin Anaesthesiol 2012, 25:229-34. | Article I PubMed

3. Brohi K: Diagnosis and management of coagulopathy after major trauma. Br J Surg 2009, 96:963-4. | Article | PubMed

4. Holcomb JB, Jenkins D, Rhee P, Johannigman J, Mahoney P, Mehta S, Cox ED, Gehrke MJ, Beilman GJ, Schreiber M, Flaherty SF, Grathwohl KW, Spinella PC, Perkins JG, Beekley AC, McMullin NR, Park MS, Gonzalez EA, Wade CE, Dubick MA, Schwab CW, Moore FA, Champion HR, Hoyt DB and Hess JR: Damage control resuscitation: directly addressing the early coagulopathy of trauma. J Trauma 2007, 62:307-10. | Article | PubMed

5. Thorsen K, Ringdal KG, Strand K, Soreide E, Hagemo J and Soreide K: Clinical and cellular effects of hypothermia, acidosis and coagulopathy in major injury. Br J Surg 2011, 98:894-907. | Article | PubMed

6. Guyton AC, Hall JE: Overview of the circulation; medical physics of pressure, flow and resistance. 11th ed. Philadelphia, Elsevier, Textbook of medical physiology 2006, 161-170. | Book

7. Ertmer C, Kampmeier T, Rehberg S and Lange M: Fluid resuscitation in multiple trauma patients. Curr Opin Anaesthesiol 2011, 24:202-8. | Article | PubMed

8. Dutton RP: Resuscitative strategies to maintain homeostasis during damage control surgery. Br J Surg 2012, 99 Suppl 1:218. | Article | PubMed

9. American College of Surgeons of Trauma Committee on Trauma: Shock. 8th ed. Chicago, Americal College of Surgeons, Advanced Trauma Life Support for Doctors ATLS Student Course Manual 2008, 55-71. I Book

10. Santry HP and Alam HB: Fluid resuscitation: past, present, and the future. Shock 2010, 33:229-41. | Article | PubMed

11. Duchesne JC, McSwain NE, Jr., Cotton BA, Hunt JP, Dellavolpe J, Lafaro K, Marr AB, Gonzalez EA, Phelan HA, Bilski T, Greiffenstein P, Barbeau JM, Rennie KV, Baker CC, Brohi K, Jenkins DH and Rotondo M: Damage control resuscitation: the new face of damage control. J Trauma 2010, 69:976-90. | Article I PubMed

12. Cotton BA, Reddy N, Hatch QM, LeFebvre E, Wade CE, Kozar RA, Gill BS, Albarado R, McNutt MK and Holcomb JB: Damage control resuscitation is associated with a reduction in resuscitation volumes and improvement in survival in 390 damage control laparotomy patients. Ann Surg 2011, 254:598605. | Article | PubMed

13. Moore FA, McKinley BA and Moore EE: The next generation in shock resuscitation. Lancet 2004, 363:1988-96. | Article | PubMed

14. Duchesne JC, Barbeau JM, Islam TM, Wahl G, Greiffenstein $P$ and McSwain NE, Jr.: Damage control resuscitation: from emergency department to the operating room. Am Surg 2011, 77:201-6. | Article | PubMed

15. Curry N, Hopewell S, Doree C, Hyde C, Brohi K and Stanworth S: The acute management of trauma hemorrhage: a systematic review of randomized controlled trials. Crit Care 2011, 15:R92. | Article | PubMed Abstract | PubMed Full Text

16. Rossaint R, Bouillon B, Cerny V, Coats TJ, Duranteau J, Fernandez-Mondejar E, Hunt BJ, Komadina R, Nardi G, Neugebauer E, Ozier Y, Riddez L, Schultz A, Stahel PF, Vincent $\mathrm{JL}$ and Spahn DR: Management of bleeding following major trauma: an updated European guideline. Crit Care 2010, 14:R52. | Article | PubMed Abstract | PubMed Full Text

17. Thompson RC: 'Physiological' $0.9 \%$ saline in the fluid 
resuscitation of trauma. J $R$ Army Med Corps 2005, 151:146-51. | Article | PubMed

18. Moore FA: The use of lactated ringer's in shock resuscitation: the good, the bad and the ugly. J Trauma 2011, 70:S15-6. | Article | PubMed

19. Coats TJ, Brazil E and Heron M: The effects of commonly used resuscitation fluids on whole blood coagulation. Emerg Med $J$ 2006, 23:546-9. | Article | PubMed Abstract | PubMed Full Text

20. Ruttmann TG, James MF and Wells KF: Effect of $20 \%$ in vitro haemodilution with warmed buffered salt solution and cerebrospinal fluid on coagulation. Br J Anaesth 1999, 82:1101. | Article | PubMed

21. Brazil EV and Coats TJ: Sonoclot coagulation analysis of in-vitro haemodilution with resuscitation solutions. J R Soc Med 2000, 93:507-10. | Article | PubMed Abstract | PubMed Full Text

22. Sorensen $B$ and Fries $D$ : Emerging treatment strategies for trauma-induced coagulopathy. Br J Surg 2012, 99 Suppl 1:4050. | Article | PubMed

23. Ruttmann TG, James MF and Aronson I: In vivo investigation into the effects of haemodilution with hydroxyethyl starch (200/0.5) and normal saline on coagulation. Br J Anaesth 1998, 80:612-6. | Article | PubMed

24. Roche AM, James MF, Bennett-Guerrero E and Mythen MG: A head-to-head comparison of the in vitro coagulation effects of saline-based and balanced electrolyte crystalloid and colloid intravenous fluids. Anesth Analg 2006, 102:1274-9. | Article | PubMed

25. Petroianu GA, Liu J, Maleck WH, Mattinger $C$ and Bergler WF: The effect of In vitro hemodilution with gelatin, dextran, hydroxyethyl starch, or Ringer's solution on Thrombelastograph. Anesth Analg 2000, 90:795-800. | Article I PubMed

26. Schreiber MA: The use of normal saline for resuscitation in trauma. J Trauma 2011, 70:S13-4. | Article | PubMed

27. Harris $\mathrm{T}$, Thomas $\mathrm{GO}$ and Brohi K: Early fluid resuscitation in severe trauma. BMJ 2012, 345:e5752. | Article | PubMed

28. Rotstein OD: Novel strategies for immunomodulation after trauma: revisiting hypertonic saline as a resuscitation strategy for hemorrhagic shock. J Trauma 2000, 49:580-3. | Article | PubMed

29. Coimbra R: $\mathbf{3 \%}$ and $\mathbf{5 \%}$ hypertonic saline. J Trauma 2011, 70:S25-6. | Article | PubMed

30. Cooper DJ, Myles PS, McDermott FT, Murray LJ, Laidlaw J, Cooper G, Tremayne AB, Bernard SS and Ponsford J: Prehospital hypertonic saline resuscitation of patients with hypotension and severe traumatic brain injury: a randomized controlled trial. JAMA 2004, 291:1350-7. | Article | PubMed

31. DuBose JJ, Kobayashi L, Lozornio A, Teixeira P, Inaba K, Lam L, Talving P, Branco B, Demetriades D and Rhee P: Clinical experience using $5 \%$ hypertonic saline as a safe alternative fluid for use in trauma. J Trauma 2010, 68:1172-7. | Article | PubMed

32. Deitch EA, Shi HP, Feketeova E, Hauser CJ and Xu DZ: Hypertonic saline resuscitation limits neutrophil activation after traumahemorrhagic shock. Shock 2003, 19:328-33. | Article | PubMed

33. Tan TS, Tan KH, Ng HP and Loh MW: The effects of hypertonic saline solution (7.5\%) on coagulation and fibrinolysis: an in vitro assessment using thromboelastography. Anaesthesia 2002, 57:644-8. | Article | PubMed

34. Coats TJ and Heron M: The effect of hypertonic saline dextran on whole blood coagulation. Resuscitation 2004, 60:101-4. I
Article I PubMed

35. Mattox KL, Maningas PA, Moore EE, Mateer JR, Marx JA, Aprahamian C, Burch JM and Pepe PE: Prehospital hypertonic saline/dextran infusion for post-traumatic hypotension. The U.S.A. Multicenter Trial. Ann Surg 1991, 213:482-91. | Article | PubMed Abstract I PubMed Full Text

36. Alam HB: Advances in resuscitation strategies. Int J Surg 2011, 9:5-12. | Article | PubMed

37. Vogt N, Bothner U, Brinkmann A, de Petriconi R and Georgieff M: Peri-operative tolerance to large-dose 6\% HES 200/0.5 in major urological procedures compared with $5 \%$ human albumin. Anaesthesia 1999, 54:121-7. | Article I PubMed

38. Ekseth K, Abildgaard L, Vegfors M, Berg-Johnsen J and Engdahl O: The in vitro effects of crystalloids and colloids on coagulation. Anaesthesia 2002, 57:1102-8. | Article | PubMed

39. Doran C: Hydroxyethyl starch for resuscitation of trauma patients. J R Army Med Corps 2007, 153:154-9. I PubMed

40. Rhee P: Albumin. J Trauma 2011, 70:S22-4. I Article I PubMed

41. Coats TJ, Brazil E, Heron M and MacCallum PK: Impairment of coagulation by commonly used resuscitation fluids in human volunteers. Emerg Med J 2006, 23:846-9. | Article | PubMed Abstract | PubMed Full Text

42. Evans PA, Garnett M, Boffard K, Kirkman E and Jacobson BF: Evaluation of the effect of colloid (Haemaccel) on the bleeding time in the trauma patient. J R Soc Med 1996, 89:101P-4P. | PubMed Abstract | PubMed Full Text

43. Trumble ER, Muizelaar JP, Myseros JS, Choi SC and Warren BB: Coagulopathy with the use of hetastarch in the treatment of vasospasm. J Neurosurg 1995, 82:44-7. | Article | PubMed

44. Ruttmann TG, James MF and Finlayson J: Effects on coagulation of intravenous crystalloid or colloid in patients undergoing peripheral vascular surgery. Br J Anaesth 2002, 89:226-30. | Article I PubMed

45. Ogilvie MP, Pereira BM, McKenney MG, McMahon PJ, Manning RJ, Namias N, Livingstone AS, Schulman Cl and Proctor KG: First report on safety and efficacy of hetastarch solution for initial fluid resuscitation at a level 1 trauma center. J Am Coll Surg 2010, 210:870-80, 880-2. | Article | PubMed

46. Ogilvie MP, Ryan ML and Proctor KG: Hetastarch during initial resuscitation from trauma. J Trauma 2011, 70:S19-21. | Article I PubMed

47. Casutt M, Kristoffy A, Schuepfer G, Spahn DR and Konrad C: Effects on coagulation of balanced $(130 / 0.42)$ and nonbalanced $(130 / 0.4)$ hydroxyethyl starch or gelatin compared with balanced Ringer's solution: an in vitro study using two different viscoelastic coagulation tests ROTEMTM and SONOCLOTTM. Br J Anaesth 2010, 105:273-81. | Article | PubMed

48. James MF, Michell WL, Joubert IA, Nicol AJ, Navsaria PH and Gillespie RS: Resuscitation with hydroxyethyl starch improves renal function and lactate clearance in penetrating trauma in a randomized controlled study: the FIRST trial (Fluids in Resuscitation of Severe Trauma). Br J Anaesth 2011, 107:693702. | Article | PubMed

49. Petroianu GA, Maleck WH, Koetter KP, Liu J and Schmitt A: Effect of in vitro hemodilution with hydroxyethyl starch and dextran on the activity of plasma clotting factors. Crit Care Med 2003, 31:250-4. I Article I PubMed

50. Ruttmann TG, Jamest MF and Lombard EH: Haemodilutioninduced enhancement of coagulation is attenuated in vitro by restoring antithrombin III to pre-dilution concentrations. 
Anaesth Intensive Care 2001, 29:489-93. | Article | PubMed

51. Ruttmann TG: Haemodilution enhances coagulation. $\mathrm{BrJ}$ Anaesth 2002, 88:470-2. | Article | PubMed

52. Ruttmann TG, Montoya-Pelaez LF and James MF: The coagulation changes induced by rapid in vivo crystalloid infusion are attenuated when magnesium is kept at the upper limit of normal. Anesth Analg 2007, 104:1475-80. | Article | PubMed

53. Ruttmann TG, Lemmens HJ, Malott KA and Brock-Utne JG: The haemodilution enhanced onset of coagulation as measured by the thrombelastogram is transient. Eur J Anaesthesiol 2006, 23:574-9. | Article | PubMed

54. Fenger-Eriksen C, Anker-Moller E, Heslop J, Ingerslev J and Sorensen B: Thrombelastographic whole blood clot formation after ex vivo addition of plasma substitutes: improvements of the induced coagulopathy with fibrinogen concentrate. $\mathrm{Br} \mathrm{J}$ Anaesth 2005, 94:324-9. | Article | PubMed

55. Ruttmann TG, James MF and Viljoen JF: Haemodilution induces a hypercoagulable state. Br J Anaesth 1996, 76:412-4. I Article | PubMed

56. Bulger EM, Cuschieri J, Warner K and Maier RV: Hypertonic resuscitation modulates the inflammatory response in patients with traumatic hemorrhagic shock. Ann Surg 2007, 245:635-41. | Article | PubMed Abstract | PubMed Full Text

57. Bulger EM: $\mathbf{7 . 5 \%}$ saline and $\mathbf{7 . 5 \%}$ saline/6\% dextran for hypovolemic shock. J Trauma 2011, 70:\$27-9. | Article | PubMed Abstract | PubMed Full Text

58. Rizoli SB, Rhind SG, Shek PN, Inaba K, Filips D, Tien H, Brenneman $\mathrm{F}$ and Rotstein $\mathrm{O}$ : The immunomodulatory effects of hypertonic saline resuscitation in patients sustaining traumatic hemorrhagic shock: a randomized, controlled, double-blinded trial. Ann Surg 2006, 243:47-57. | Article | PubMed Abstract | PubMed Full Text

59. Dretzke J, Sandercock J, Bayliss S and Burls A: Clinical effectiveness and cost-effectiveness of prehospital intravenous fluids in trauma patients. Health Technol Assess 2004, 8:iii, 1-103. | Article | PubMed

\section{Citation:}

Kaczynski J, Wilczynska M, Hilton J and Fligelstone L: Impact of crystalloids and colloids on coagulation cascade during trauma resuscitation-a literature review. Emergency Medicine and Health Care 2013, 1:1. http://dx.doi.org/10.7243/2052-6229-1-1 